\title{
Permeabilitas Tanah Berbagai Tipe Penggunaan Lahan di Tanah Aluvial Pesisir DAS Cimanuk, Indramayu
}

\author{
Asep Mulyono1, Hilda Lestiana² dan Anna Fadilah² \\ 1UPT Loka Uji Teknik Penambangan dan Mitigasi Bencana, Liwa LIPI; email : asepliwa@yahoo.co.id \\ 2Pusat Penelitian Geoteknologi LIPI
}

\begin{abstract}
ABSTRAK
Pesisir Indramayu termasuk wilayah DAS Cimanuk dengan jenis tanah Aluvial/Entisols. Pengetahuan berapa besar kemampuan tanah Aluvialdalam pergerakan air (permeabilitas) merupakan aspek penting dalam hubungannya dengan lingkungan. Studi variasi tingkat permeabilitas tanah akibat berbagai tipe penggunaan lahan pada tanah Aluvial telah dilakukan. Survei lapangan dilakukan dengan pengambilan contoh tanah. Contoh tanah untuk penetapan sifat permeabilitas tanah berdasarkan metode constan head. Analisis kimia tanah dilakukan untuk kandungan fraksi organik tanah, tekstur tanah.Hasil analisis menunjukkan lahan hutan memberikan hasil yang lebih cepat dibanding tipe penggunaan lahan lain. Kebun monokultur menghasilkan rata-rata permeabilitas yang lebih tinggi dibanding lahan kebun campuran.
\end{abstract}

Kata Kunci : Permeabilitas, organik, tekstur, tanah, Indramayu

\begin{abstract}
Indramayu coastal were included into Cimanuk watersheds with an Alluvial or Entisols soil type. Knowledge of how much ability of soil water movement (permeability) of Alluvial soil types is an important aspect in relation to the environment. Studies on the variety of soil permeability due to various types of land use in the alluvial soil has been carried out. The field survey was carried out by taking soil samples. The soil samples were taken for the determination of soil permeability properties based constan headmethods. Soil chemical analysis was done to determine the organic fraction of the soil, soil texture. The analysis showed that the forest area gives faster results compared to the other type of land use. Monoculture gardens produce a higher average permeability than mixed gardens.
\end{abstract}

Keywords: Permeability, organic, texture, Indramayu

Citation: Mulyono, A., Lestiana, H.,dan Fadilah, A. (2019). Permeabilitas Tanah Berbagai Tipe Penggunaan Lahan di Tanah Aluvial Pesisir DAS Cimanuk, Indramayu. Jurnal Ilmu Lingkungan, 17(1), 1-6, doi:10.14710/jil.17.1.1-6

\section{Pendahuluan}

Wilayah pesisir Indramayu yang termasuk kedalam wilayah daerah aliran sungai (DAS) Cimanuk merupakan wilayah yang secara geologis berasal dari endapan aluvium. Hasil endapan tersebut berasal dari sedimentasi Sungai Cimanuk yang bermuara di wilayah ini yang berdasarkan Pusat Penelitian Geologi Kelautan (2016), pesisir timur Indramayu mengalami akresi dan membentuk delta baru dengan tipe telapak kaki burung (birdfoot-type delta) dengan kandungan lumpur sungai Cimanuk dapat mencapai rata-rata 53,6 juta ton/tahun.

Wilayah ini merupakan daerah hilir dari aliran sungai-sungai yang sangat potensial sebagai sumber air bagi kebutuhan masyarakat, baik untuk kepentingan usaha pertanian, usaha industri maupun bahan baku air bersih. Namun, selain diuntungkan dengan besarnya kapasitas air permukaan, sisi lain air permukaan menjadi penyebab terjadinya penggenangan/banjir. Tingginya potensi banjir di wilayah ini selain topografi wilayah yang sangat datar juga faktor geologis dan jenis tanahnya. Hasil endapan Aluvium (Achidan dan Sudana, 1992) ini menghasilkan jenis tanah Aluvial atau tanah Entisols menurut klasifikasi Soil Taxonomy (Soil Survey Staff, 1990) dengan sub grupSodic Psammaquents, yaitu tanah Entisols yang berada di dataran pasang surut dengan rejim kelembaban tanah aquic. Rendahnya kemampuan tanah dalam meresapkan air jenis tanah ini menambah tiingginya kejadian banjir di wilayah ini.

Pergerakan air di dalam tanah merupakan aspek penting dalam hubungannya dengan bidang pertanian. Beberapa proses penting, sepertimasuknya air ke dalam tanah, pergerakan air ke zona perakaran, keluarnya air 
lebih (excess water) atau drainase, aliran permukaan, danevaporasi, sangat dipengaruhi oleh kemampuan tanah untuk melewatkan air (Dariah dkk., 2006).Permeabilitas tanah menunjukkan kemampuan tanah dalam meloloskan air(Klute dan Dirksen, 1986), sedangkan menurut Hakim dkk., (1986), permeabilitas adalah untuk transfer air atau udara. Secara kuantitatif permeabilitas tanah/hantaran hidrolik adalah kecepatan bergeraknya suatu cairan pada media berpori, atau didefinisikan sebagai kecepatan air untuk melewati tanah pada periode waktu tertentu yang dinyatakan dalam sentimeter per jam (Baver, 1959; Foth, 1984).

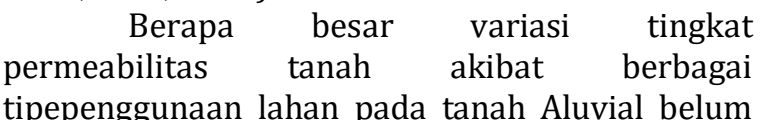

banyak diketahui. Oleh sebab itu, studi kemampuan tanah dalam melalukan air (permeabilitas tanah) sebagai akibat berbagai pola penggunaan lahan sangat penting untuk dilakukan.

\section{Metodologi \\ 2.1. Lokasi dan Waktu Penelitian}

Penelitian dilaksanakan di wilayah pesisir DAS Cimanuk, yang termasuk dalam wilayah administratif Kabupaten Indramayu, Propinsi Jawa Barat. Secara geografis lokasi studi terletak membujur pada posisi 108'9' 43"- 108'28' 27" Bujur Timur dan 6012' 38'- 6031' 41" Lintang Selatan (Gambar 1) dengan ketinggian wilayah pada umumnya berkisar antara 0-18 meter diatas permukaan laut. Sebagian besar wilayah studi berupa dataran dengan kemiringan antara 0-2\%.

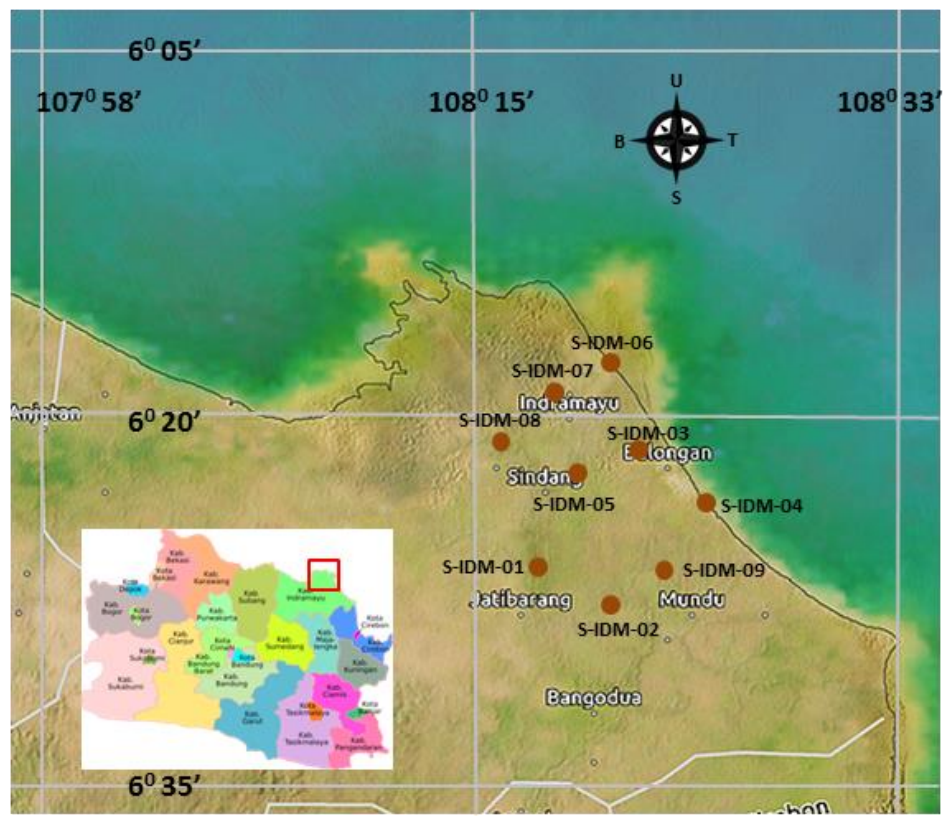

Gambar 1. Lokasi Penelitian

\subsection{Metode Penelitian}

Penelitian menggunakan metode melalui survey secara langsung. Survei lapangan dilakukan dengan pengambilan contoh tanah yang diambil secara komposit pada lapisan olah (0-20 $\mathrm{cm}$ ) dan utuh berdasarkan petunjuk teknis pengamatan tanah (Balai penelitian Tanah, 2004). Variabel yang di ukur diantaranya: permeabilitas, fraksi organik tanah dan tekstur tanah.Pengambilan contoh tanah utuh dilakukan dengan menggunakan ring atau tabung untuk penetapan sifat permeabilitas tanahberdasarkan metode constan head (Klute dan Dirksen,1986). Pengukuran permeabilitas tanah dilakukan melalui tahapan sebagai berikut : (a) contoh tanah dalam ring direndam dalam air pada bak perendaman dengan kedalaman sedikit di bawah bagian atas ring selama lebih dari 12 jam atau sampai tanah nampak basah; (b) setelah proses penjenuhan selesai, bagian atas dari ring yang berisi contoh tanah dihubungkan dengan ring kosong, menggunakan pita selotif. Selama proses penyambungan, contoh tanah tetap berada dalam air rendaman; (c) selanjutnya contoh tanah dipindahkan ke alat pengukuran, kemudian air dialirkan ke alat tersebut dengn menjaga agar tinggi air di atas contoh tanah tetap konstan; (d) lakukan pengukuran volume air yang keuar melalui massa tanah dengan pengukuran pertama setelah 6 jam dan pengukuran selanjutnya interval satu jam. Sedangkan contoh tanah komposit, yaitu contoh yang dikumpulkan dari beberapa titik pengamatan yang dicampur merata menjadi satu contoh yang homogen, digunakan untukvariabel kandungan fraksi organik tanah (Balai Penelitian Tanah, 2005), tekstur tanah dengan metode pipet (Balai Penelitian Tanah, 
2005). Pengolahan data dilakukan dengan microsoft excel.

\section{Hasil dan Pembahasan}

Jenis tanah di wilayah studi (tergolong pada tanah Aluvial Kelabu dan Aluvial Coklat. Tanah Aluvial atau Entisols menurut Soil Taxonomy (Soil Survey Staff, 1990)berasal dari endapan baru, berlapis-lapis, bahan organik jumlahnya berubah tidak teratur dengan kedalaman.Lokasi pengukuran dan pengambilan sampel tanah (Tabel 1) berada pada kemiringan lereng datar-berombak $(<5 \%)$ yang didasarkan pada satuan geologi Aluvial (S-IDM-01, S-IDM-02, dan S-IDM-09), Endapan pantai (S-IDM-03, S-IDM04), Endapan banjir (S-IDM-05, S-IDM-07, S-IDM08), dan Endapan punggungan pantai (S-IDM-06).

Tabel 1. Titik Lokasi Pengukuran dan Pengambilan Sampel

\begin{tabular}{|c|c|c|c|c|c|}
\hline No. & Titik Sampel & $\begin{array}{c}\text { Koordinat } \\
\text { X }\end{array}$ & $\begin{array}{c}\text { Koordinat } \\
\text { Y }\end{array}$ & Satuan Geologi & Penggunaan Lahan \\
\hline 1 & S-IDM-01 & $108^{\circ} 17^{\prime} 36^{\prime \prime}$ & $-6^{\circ} 23^{\prime} 13^{\prime \prime}$ & Aluvial & Kebun Campuran \\
\hline 2 & S-IDM-02 & $108^{\circ} 19^{\prime} 45^{\prime \prime}$ & $-6^{\circ} 24^{\prime} 16^{\prime \prime}$ & Aluvial & Kebun Monokultur Mangga \\
\hline 3 & S-IDM-03 & $108^{\circ} 20^{\prime} 37^{\prime \prime}$ & $-6^{\circ} 19^{\prime} 55^{\prime \prime}$ & Endapan Pantai & Hutan Sekunder \\
\hline 4 & S-IDM-04 & $108^{\circ} 22^{\prime} 44^{\prime \prime}$ & $-6^{\circ} 21^{\prime} 25^{\prime \prime}$ & Endapan Pantai & Kebun Campuran \\
\hline 5 & S-IDM-05 & $108^{\circ} 18^{\prime} 45^{\prime \prime}$ & $-6^{\circ} 20^{\prime} 35^{\prime \prime}$ & Endapan Dataran Banjir & Kebun Campuran \\
\hline 6 & S-IDM-06 & $108^{\circ} 19^{\prime} 46^{\prime \prime}$ & $-6^{\circ} 17^{\prime} 28^{\prime \prime}$ & Endapan punggungan pantai & Kebun Campuran \\
\hline 7 & S-IDM-07 & $108^{\circ} 18^{\prime} 5^{\prime \prime}$ & $-6^{\circ} 18^{\prime} 17^{\prime \prime}$ & Endapan Dataran Banjir & Kebun Campuran \\
\hline 8 & S-IDM-08 & $108^{\circ} 16^{\prime} 29^{\prime \prime}$ & $-6^{\circ} 19^{\prime} 39^{\prime \prime}$ & Endapan Dataran Banjir & Sawah \\
\hline 9 & S-IDM-09 & $108^{\circ} 21^{\prime} 25^{\prime \prime}$ & $-6^{\circ} 23^{\prime} 18^{\prime \prime}$ & Aluvial & Sawah \\
\hline
\end{tabular}

Tipe penggunaan lahan masing-masing (Gambar 2), yaitu pada lahan dengan tipe penggunaan lahan Kebun Campuran (S-IDM-01, S-IDM-04,S-
IDM-05, S-IDM-06, S-IDM-07), kebun mangga monokultur (S-IDM-02), hutan kota sekunder (SIDM-03), sawah (S-IDM-08 dan S-IDM-09).
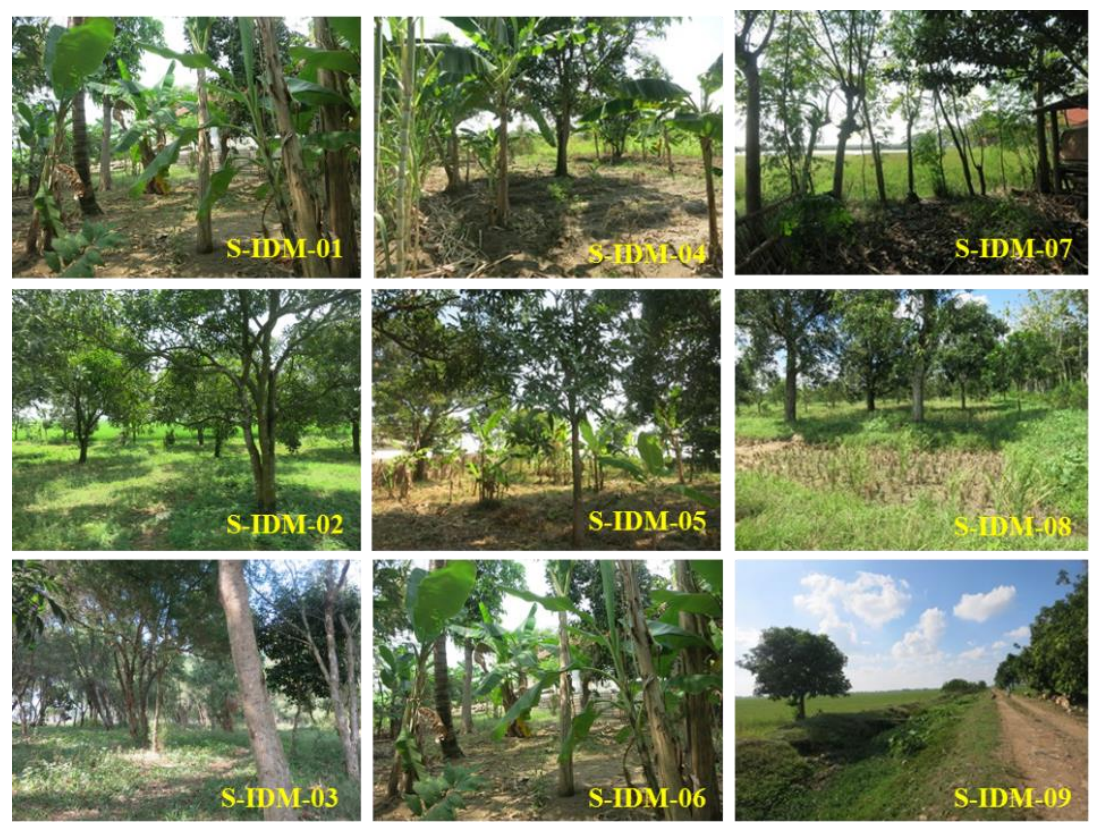

Gambar 2. Tipe Penggunaan Lahan Lokasi Studi

Tipe penggunaan lahan sawah di lokasi studi merupakan sawah irigasi teknis, sedangkan penggunaan lahan kebun campuran dilakukan dengan metode minimum tillagedimana yakni hanya mengolah pada bagian lahan yang dirasa perlu untuk pertumbuhan tanaman saja dan tidak melakukan pengolahan keseluruhan area lahan.

Jenis tanah di wilayah studi yang merupakan tanah Aluvialmerupakan tanah yang belum mengalami perkembangan yang sempurna, dan hanya memiliki horizon A yang marginal.
Umur yang masih muda menjadikan tanah Aluvial masih miskin kandungan organik sehingga keadaannya kurang menguntungkan bagi sebagian tumbuhan. Hanya terdapat epipedon ochrik, histik atau sulfurik, kandungan pasir kurang dari 60 \%.Pada Tabel 2 memperlihatkan kandungan masing-masing fraksi tanah yang terdiri atas kandungan pasir, debu dan liat dengan perbedaantekstur dan fraksi besar butir tanah yang berbeda di setiap sampel tanah. 
Tabel 2. Kandungan Fraksi dan Kelas Tektur Tanah

\begin{tabular}{clcclll}
\hline \hline No. & Titik Sampel & Pasir & Debu & Liat & Tekstur & Fraksi Besar Butir \\
\hline 1 & S-IDM-01 & 4.5 & 42.3 & 54.1 & Liat berdebu & halus(h) \\
2 & S-IDM-02 & 1.2 & 29.1 & 69.7 & Liat & halus(h) \\
3 & S-IDM-03 & 7.0 & 18.5 & 74.5 & Liat & aglus(h) \\
4 & S-IDM-04 & 73.2 & 8.3 & 18.4 & Lempung berpasir & hasar \\
5 & S-IDM-05 & 2.0 & 34.1 & 63.9 & Liat & agalus(h) halus (ah) \\
6 & S-IDM-06 & 33.3 & 27.8 & 38.8 & Lempung berliat & halus(h) \\
7 & S-IDM-07 & 31.2 & 20.9 & 47.9 & Liat & agak kasar \\
8 & S-IDM-08 & 72.9 & 9.6 & 17.5 & Lempung berpasir & halus(h) \\
9 & S-IDM-09 & 0.5 & 25.2 & 74.3 & Liat & \\
\hline
\end{tabular}

Tekstur tanah lokasi penelitian secara umum merupakan didominasi oleh kategori liat dengan beberapa sampel yang mengandung pasir $>30 \%$. Tekstur tanah lempung berpasir dicirikan dengan rasa agak kasar, membentuk bola agak keras tetapi mudah hancur, serta melekat. Tekstur tanah liat berdebu dicirikan dengan rasa agak licin, membentuk bola dalam keadaan kering sukar dipijit, mudah digulung, serta melekat sekali. Tekstur tanah lempung berliat dicirikan dengan Rasa agak kasar, membentuk bola agak teguh (kering), membentuk gulungan jika dipirid tetapi mudah hancur, serta melekat sedang. Sedangkan tekstur tanah liat dicirikan dengan rasa berat, membentuk bola sempurna, bila kering sangat keras, sangat melekat.Secara umum tanah berfraksi halus. Klasifikasi permeabilitas tanah didasarkan pada Uhland dan O'Neil (1951) dalam LPT (1979) yang disajikan pada Tabel 3.

Tabel 3. Klasifikasi Permeabilitas Tanah Berdasarkan Uhland dan O'Neil (1951)

\begin{tabular}{lc}
\hline \hline & Kelas \\
\hline Sangat lambat & Permeabilitas (cm/jam) \\
Lambat & $0.0125-0.5$ \\
Agak lambat & $0.5-2.0$ \\
Sedang & $2.0-6.25$ \\
Agak cepat & $6.25-12.5$ \\
Cepat & $12.5-25.5$ \\
Sangat cepat & $>25.5$ \\
\hline Sumber : LPT (1979) &
\end{tabular}

Hasil pengukuran masing-masing sampel tanah ditampilkan pada Tabel 4, dimanapermeabilitas tanah lokasi S-IDM-04, SIDM-05, S-IDM-05, S-IDM-07, S-IDM-08 dan SIDM-09dikategorikan agak lambat, permeabilitas tanah kategori agak cepat terdapat pada lokasi SIDM-03, sedangkan permeabilitas tanah kategori sedang pada lokasi S-IDM-01 dan S-IDM-02. Tanah bertekstur liat secara umum menghasilkan tanah yang memiliki nilai permeabilitas lambat. Hal ini diakibatkan oleh ukuran pori pada tanah bertekstur liat memiliki ruang pori yang kecil. Menurut Dariah dkk., (2006), ukuran pori dan adanya hubungan antar pori-pori sangat menentukan apakah tanah mempunyai permeabilitas rendah atau tinggi dimana permeabilitas juga mungkin mendekati nol apabila pori-pori tanah sangat kecil, seperti pada tanah liat.

Banyak faktor yang mempengaruhi tingkat permeabilitas tanah, terutama tekstur, struktur, stabilitas agregat, porositas, distribusi ukuran pori, kekontinyuan pori dan kandungan bahan organik (Hillel, 1971). Permeabilitas tanah meningkat bila (a) agregasi butir-butir tanah menjadi remah, (b) adanya saluran bekas lubang akar tanaman yang terdekomposisi, (c)adanya bahan organik, dan (d) porositas tanah yang tinggi (Mohr dan Bahren, 1954).

Tabel 4. Kandungan Total Fraksi Organik dan Permeabilitas Tanah di Lokasi Penelitian

\begin{tabular}{|c|c|c|c|}
\hline No. & Titik Sampel & Bahan Organik (\%) & Permeabilitas (cmjam) \\
\hline 1 & S-IDM-01 & 4.28 & 4.50 \\
\hline 2 & S-IDM-02 & 3.30 & 3.26 \\
\hline 3 & S-IDM-03 & 7.19 & 7.34 \\
\hline 4 & S-IDM-04 & 1.68 & 0.31 \\
\hline 5 & S-IDM-05 & 3.47 & 0.39 \\
\hline 6 & S-IDM-06 & 2.92 & 0.48 \\
\hline 7 & S-IDM-07 & 5.58 & 0.46 \\
\hline 8 & S-IDM-08 & 1.60 & 0.09 \\
\hline 9 & S-IDM-09 & 2.77 & 0.01 \\
\hline
\end{tabular}

Tabel 4. memperlihatkan kandungan bahan organik kategori sedang ditemukan pada lokasi S-IDM-01 dan S-IDM-05, kandungan bahan organik kategori tinggi pada lokasi S-IDM-03 dan
S-IDM-07, sedangkan kategori sangat rendahrendah berada di lokasi S-IDM-02, S-IDM-04, SIDM-06, S-IDM-08 dan S-IDM-09. 


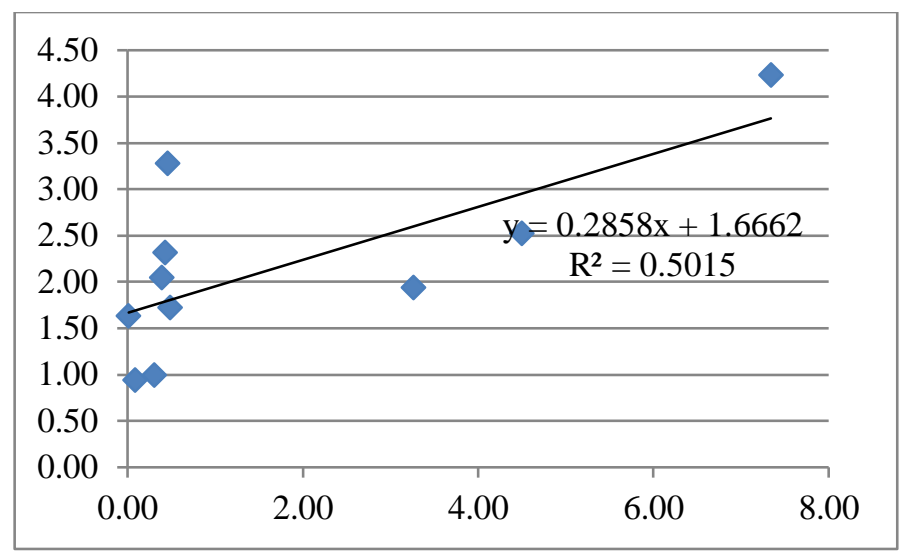

Gambar 3. Grafik korelasi bahan organik dan permeabiitas tanah

Terdapat korelasi positif antara kandungan bahan organik tanah dengan nilai permeabilitas tanah (Gambar 3). Pada tanah yang mengandung pasiran, kandungan bahan organik tanah dapat merubah struktur tanah dari berbutir tunggal menjadi bentuk gumpal, sehingga meningkatkan derajat struktur dan ukuran agregat atau meningkatkan kelas struktur dari halus menjadi sedang atau kasar (Scholes dkk.,
1994), dengan demikian meningkatkan kapasitas tanah dalam mengalirkan air.

Pengaruh tipe penggunaan lahan sangat berpengaruh terhadap kandungan bahan organik tanah. Tanah pada lokasi S-IDM-03 yang merupakan wilayah hutan sekunder memberikan tingkat permeabilitas tanah lebih cepat dibanding tipe penggunaan lain dengan kategori agak cepat seiring dengan tingginya kandungan bahan organik tanah (Tabel 5).

Tabel 5. Rata-Rata Bahan Organik dan Permeabilitas Tanah Berbagai Penggunaan Lahan

\begin{tabular}{llcc}
\hline \hline No. & \multicolumn{1}{c}{ Penggunaan Lahan } & Bahan Organik (\%) & Permeabilitas (cmjam) \\
\hline 1 & Kebun Campuran & 3.59 & 1.23 \\
2 & Kebun Monokultur & 3.30 & 3.26 \\
3 & Hutan Sekunder & 7.19 & 7.34 \\
4 & Sawah & 2.18 & 0.05 \\
\hline
\end{tabular}

Kandungan tertinggi bahan organik terdapat pada hutan sekunder di lokasi S-IDM-03 dikarenakan lahan ini selain banyak mendapatkan suplai bahan organik dari pepohonan dan vegetasi lain yang ada di lahan ini juga karena lahan ini tidak dibudidayakan, sehingga proses dekomposisi bahan organik akan berjalan lambat, berbeda dengan yang terjadi pada lahan yang dibudidayakan, di mana proses dekomposisi bahan organik berjalan lebih cepat.Semakin lambat terdekomposisi maka keberadaannya di permukaan tanah menjadi lebih lama (Hairiah dkk., 2004).Semakin banyak bahan organik di dalam tanah maka akan meningkatkan kadar air pada kapasitas lapang, akibat dari meningkatnya pori yang berukuran menengah (meso) dan menurunnya pori makro, sehingga daya menahan air meningkat, dan berdampak pada peningkatan ketersediaan air untuk pertumbuhan tanaman (Scholes dkk., 1994).

Selain faktor kandungan organik, dampak pengolahan tanah mempengaruhi kapasitas permeabilitas tanah. Pemadatan oleh hujan, hewan ataupun peralatan yang berat secara drastis dapat mengurangi kemampuan tanah untuk menyerap air dengan tertutupnya pori-pori tanah. (Lee, 1990). Tanah pada lokasi S-IDM-08 dan S-IDM-08yang didominasi merupakan wilayah sawah memberikan tingkat permeabilitas tanah yang tergolong lambat. Hasil analisis menunjukkan tanah berfraksi halus dengan kandungan bahan organik rendah. Tanah berfraksi halus secara umum menghasilkan tanah yang memiliki nilai permeabilitas yang rendah.

\section{Kesimpulan}

Permeabilitas tanah masing-masing tipe penggunaan lahan berbeda sesuai dengan faktor yang mempengaruhinya. Kandungan fraksi tekstur (pasir, debu dan liat), bahan organik dan pengolahan tanah penggunaan lahan memberikan pengaruh terhadap besar kecilnya permeabilitas tanah. Permeabilitas tanah pada lahan hutan sekunder memberikan hasil yang lebih cepat dibanding tipe penggunaan lahan kebun campuran, kebun monokultur dan sawah. Tipe penggunaan lahan kebun monokultur menghasilkan rata-rata permeabilitas yang lebih tinggi dibanding lahan kebun campuran.

\section{UCAPAN TERIMA KASIH}

Penulis mengucapkan terima kasih yang sebesar-besarnya kepada Kelompok Penelitian Air dan Lingkungan (KAL) Pusat Penelitian Geoteknologi LIPI, Tim penelitian kegiatan Pesisir DAS Cimanuk Pusat Penelitian 
Geoteknologi LIPI dan Pusat Penelitian Limnologi LIPI sebagai penyedia dana penelitian ini.

\section{DAFTAR PUSTAKA}

Achidan, A., dan Sudana, D. 1992. Peta Geologi lembar Indramayu skala 1:100.000. Pusat Penelitian dan Pengembangan Geologi

Balai Penelitian Tanah. 2005. Petunjuk Analisis Kimia Tanah, Tanaman, Air dan Pupuk. Pusat Penelitian dan Pengembangan Tanah dan Agroklimat. Badan Penelitian dan Pengembangan Pertanian. Departemen Pertanian.

Baver, L.D. 1959. Soil Physics. 3rd ed. John Willey and Sons, Inc., New York.

Dariah, A., Yusrial, dan Mazwar. 2006. Penetapan Kondukstivitas Hidrolik Tanah dalam Keadaan Jenuh: Metode Laboratorium: Sifat Fisik Tanah dan Metode Analisisnya. Balai Besar Litbang Sumberdaya Lahan Pertanian. Badan Penelitian dan Pengembangan Pertanian, Departemen Pertanian.

Foth, H.D. 1984. Fundamental of Soil Science. John Willey and Sons, New York.

Hairiah, K., D. Suprayogo, B. Widianto, E. Suhara, A. Mardiastuning, C. Prayogo, R.H. Widodo, dan Rahayu,S. 2004. Alih Guna Lahan Hutan Menjadi Lahan Agroforestri Berbasis Kopi: Ketebalan Serasah, Populasi Cacing Tanah dan Makropositas Tanah. Agrivita. Malang.
Hakim, N.M., Y. Nyakba, A.M. Lubis, S.G. Nugroho, M.R. Saul, M.A. Diha, Go.Ban, Hong, dan H.H. Bailey. 1986. Dasar-dasar Ilmu Tanah. UNILA. Lampung.

Klute, A., and Dirksen. 1986. Hidraulic conductivity and diffusivity: Laboratory method. p. 687-732. In Klute, A. (Ed.). Methods of Soil Analysis Part I. Physical and Mineralogical Methods. Second Edition.

Lee, R. 1990. Hidrologi Hutan. Gadjah Mada University Press. Yogyakarta.

Lembaga Penelitian Tanah, (LPT),(1979). Penuntun Analisa Fisika Tanah. Lembaga Penelitian Tanah. Badan Litbang Pertanian.

Mohr, E.J.C. and Baren V.F.A. 1954. Tropical Soil. Interscience Publishing. London.

Pusat Penelitian Geologi kelautan. 2016. Proses Pertumbuhan Delta Baru Sungai Cimanuk Hingga Tahun 2002, Di Pantai Timur Kabupaten. INDRAMAYUhttp://www.mgi.esdm.go.id/conte nt/proses-pertumbuhan-delta-baru-sungaicimanuk-hingga-tahun-2002-di-pantai-timurkabupaten. Diunduh tanggal 21 Januari 2016.

Scholes, M.C., Swift, O.W. Heal, P.A. Sanchez, JSI. Ingram and R. Dudal. 1994. Soil Fertility research in response to demand for sustainability. In The biological managemant of tropical soil fertility (Eds Woomer, Pl. and Swift, MJ.) John Wiley \& Sons. New York.

Soil Survey Staff. 1990. Keys for Soil Taxonomy. SMSS Technical Monograph No. 19 Fourth Edition. Cornell University. 